\title{
Hypotension in pregnant women: a population-based case-control study of pregnancy complications and birth outcomes
}

\author{
Ferenc Bánhidy ${ }^{1}$, Nándor Ács ${ }^{1}$, Erzsébet H Puhó ${ }^{2}$ and Andrew E Czeizel ${ }^{2}$
}

Hypotension is frequent in pregnant women; nevertheless, its association with pregnancy complications and birth outcomes has not been investigated. Thus, the aim of this study was to analyze the possible association of hypotension in pregnant women with pregnancy complications and with the risk for preterm birth, low birthweight and different congenital abnormalities (CAs) in the children of these mothers in the population-based data set of the Hungarian Case-Control Surveillance of CAs, 1980-1996. Prospectively and medically recorded hypotension was evaluated in 537 pregnant women who later had offspring with CAs (case group) and 1268 pregnant women with hypotension who later delivered newborn infants without CAs (control group); controls were matched to sex and birth week of cases (in the year when cases were born), in addition to residence of mothers. Over half of the pregnant women who had chronic hypotension were treated with pholedrine or ephedrine. Maternal hypotension is protective against preeclampsia; however, hypotensive pregnant women were at higher risk for severe nausea or vomiting, threatened abortion (hemorrhage in early pregnancy) and for anemia. There was no clinically important difference in the rate of preterm births and low birthweight newborns in pregnant women with or without hypotension. The comparison of the rate of maternal hypotension in cases with 23 different CAs and their matched controls did not show a higher risk for CAs (adjusted OR with $95 \%$ confidence intervals: $0.66,0.49-0.84$ ). In conclusion, a higher risk for CAs and other adverse birth outcomes was not found in the offspring of pregnant women with hypotension, but maternal hypotension was associated with a higher risk of some pregnancy complications.

Hypertension Research (2011) 34, 55-61; doi:10.1038/hr.2010.172; published online 30 September 2010

Keywords: congenital abnormalities; hypotension; hypotension drugs; pregnancy; pregnancy complications

\section{INTRODUCTION}

Hypertension is a common medical condition that has multiple manifestations, including primary and secondary hypertension disease, preeclampsia and gestational hypertension in pregnant women. ${ }^{1-3}$ However, the study of the other end of the blood pressure spectrum (that is, hypotension) has been neglected in pregnant women ${ }^{4}$ even though hypotension occurs frequently during pregnancy. We were unable to find controlled epidemiological studies regarding the effect of hypotension and related drug treatments for pregnancy complications or adverse birth outcomes in the medical literature. ${ }^{5}$ This medical attitude is partially understandable because hypotension is not a disease; rather, it is a symptom of low blood pressure in individuals and is generally not associated with serious complications.

Hypotension occurs frequently in Hungarian pregnant women, and obstetricians, in general after consultation with specialists, prefer to treat the more severe and unpleasant symptomatic manifestations of hypotension during pregnancy. However, the potential teratogenic/ fetotoxic risk of hypotension drug treatments frequently causes anxiety for both pregnant women and their physicians.

Thus, the primary aim of our study was to evaluate the possible association of maternal hypotension during pregnancy with pregnancy complications and/or adverse birth outcomes, particularly the risk of structural birth defects (that is, congenital abnormalities (CAs)) in the population-based data set of the Hungarian Case-Control Surveillance of CAs (HCCSCA). ${ }^{6}$ The secondary aim was to estimate the possible teratogenic/fetotoxic effect of hypotension drugs in pregnant women.

\section{METHODS}

Study subjects

Cases affected with CAs were selected from the data set of the Hungarian Congenital Abnormality Registry (HCAR) from 1980 to $1996^{7}$ for the HCCSCA. A report of CA cases by physicians to the HCAR is mandatory from birth until the end of the first postnatal year. Most cases are reported by obstetricians and pediatricians. In Hungary, almost all deliveries take place in in-patient obstetric clinics, and the birth attendants are obstetricians.

1Second Department of Obstetrics and Gynecology, Semmelweis University, School of Medicine, Budapest, Hungary and ${ }^{2}$ Foundation for the Community Control of Hereditary Diseases, Budapest, Hungary

Correspondence: Dr AE Czeizel, Foundation for the Community Control of Hereditary Diseases, A.E., Törökvész lejtő 32, Budapest H-1026, Hungary.

E-mail: czeizel@interware.hu

Received 15 February 2010; revised 9 June 2010; accepted 1 July 2010; published online 30 September 2010 
Pediatricians work in the neonatal units of in-patient obstetric clinics or in various in-patient and outpatient pediatric clinics. Autopsy was mandatory for all infant deaths and was common (about $80 \%$ ) in stillborn fetuses during the study period. Pathologists send a copy of the autopsy report to the HCAR if defects are identified in stillbirths or infant deaths. Since 1984, fetal defects diagnosed in prenatal diagnostic centers with or without termination of pregnancy have also been included in the HCAR.

CAs cannot be regarded as a single homogeneous birth outcome because teratogenic factors, such as maternal diseases, do not uniformly increase the rates of all CAs but rather tend to increase the occurrence of one or a limited number of specific CAs. Therefore, 24 isolated CA groups and one multiple-CA group were evaluated separately in the HCCSCA. The term 'isolated CAs' refers to only one affected organ, whereas 'multiple CAs' refers to the concurrence of two or more CAs in the same person affecting at least two different organ systems. In addition, CAs were differentiated into three groups: lethal (defects cause either stillbirth and infant death or pregnancies were terminated because of fetal defect in more than $50 \%$ of cases), severe (without medical intervention, CAs cause handicap or death) and mild (CAs require medical intervention but life expectancy is good). Lethal and severe CAs together constitute 'major CAs. ${ }^{7}$ Minor anomalies or morphological variants without serious medical or cosmetic consequences were recorded in the HCAR, but they were excluded from the estimation of rates of different CAs.

The recorded total (birth+fetal) prevalence of CA cases diagnosed from the second trimester of pregnancy through to 1 year of age was 35.0 per 1000 informative offspring (live-born infants, stillborn fetuses and electively terminated malformed fetuses) in the HCAR from 1980 to 1996, and about $90 \%$ of major CAs were recorded in the HCAR during the 17-year study period. ${ }^{8}$ The proportion of live-born infants, stillborn fetuses and electively terminated malformed fetuses was $97.1,1.1$ and $1.8 \%$, respectively.

There were three exclusion criteria for CA cases from the HCAR for the data set of the HCCSCA: (i) CAs reported after 3 months of birth or pregnancy termination $(77 \%$ of cases were reported during the first three postnatal months, most of the remaining cases included mild CAs), (ii) three mild CAs (congenital dysplasia of the hip and inguinal hernia or hemangioma) and (iii) CA syndromes caused by major gene mutations or chromosomal aberrations of preconceptional origin.

Controls were defined as newborn infants without CA, and they were selected from the National Birth Registry of the Central Statistical Office for the HCCSCA. In general, two controls were matched to every case according to sex, birth week in the year when cases were born, and district of mothers' residence.

\section{Collection of exposure and confounding data}

Three sources of data were evaluated.

(1) Prospective medically recorded data: Mothers were asked in an explanatory letter to send us their prenatal maternity chart ('logbook' in Hungary) and other medical records, particularly discharge summaries, regarding their diseases during the study pregnancy and their child's CA. Prenatal care was mandatory for pregnant women in Hungary. If a woman failed to visit the prenatal care clinic, she could not receive a maternity grant or have maternity leave. Thus, nearly $100 \%$ of pregnant women visited prenatal care clinics an average of seven times during their pregnancies. The first visit was between the sixth and twelfth gestational week. The task of obstetricians was to record all pregnancy complications, maternal diseases and related drug prescriptions in the prenatal maternity chart.

(2) Retrospective self-reported maternal information: A structured questionnaire with a list of medicinal products (drugs and pregnancy supplements) and diseases, as well as a printed informed consent form, was also mailed to the mothers immediately after the selection of cases and controls. The questionnaire requested information on pregnancy complications and maternal diseases, on medicinal products taken during pregnancy according to gestational month and on family history of CAs. To standardize the answers, mothers were asked to read the enclosed lists of medicinal products and diseases as a memory aid before they filled in the questionnaire.

The mean \pm s.d. time elapsed between the birth or pregnancy termination and the return of the 'information package' (questionnaire, chart, discharge summary and informed consent form) in our prepaid envelope was $3.5 \pm 1.2$ and $5.2 \pm 2.9$ months in the case and control groups, respectively.

(3) Supplementary data collection: Regional nurses were asked to visit all non-respondent case mothers at home. They helped mothers to fill in the same questionnaire, evaluated the available medical records and obtained data regarding smoking and drinking habit through a cross-interview of mothers and their close relatives living together. Finally, the so-called 'family consensus' was recorded. Smoking habit was evaluated on the basis of the number of cigarettes smoked per day. Those consuming alcohol were classified into three groups: (i) abstinent or occasional drinker (less than one drink per week), (ii) regular drinkers (from one drink per week to one drink daily) and (iii) hard drinkers (more than one drink per day). Regional nurses visited only 200 nonrespondent control mothers and 600 respondent control mothers as a part of two validation studies, ${ }^{9,10}$ because the ethics committee considered this followup to be disturbing to the parents of healthy children. Regional nurses used the same methods in control mothers as in non-respondent case mothers.

Overall, the necessary information was available for $96.3 \%$ of cases $(84.4 \%$ from mail reply, $11.9 \%$ from nurse visit) and $83.0 \%$ of controls (81.3\% from mail reply, $1.7 \%$ from nurse visit). The informed consent form was signed by $98 \%$ of mothers, and names and addresses were deleted for the remaining $2 \%$.

In the present study, 17 years of data from the HCCSCA collected between 1980 and 1996 are evaluated because the data collection was changed after 1997 (all mothers are now visited by regional nurses). This recent change of data collection had not been validated at the time of this analysis.

\section{Diagnostic criteria of hypotension}

The distribution of blood pressure in the population is continuous. Thus, there is no obvious natural threshold between normal and high/low blood pressure as in other diseases that are so-called qualitative diseases (yes or no). Expert recommendations suggest that hypotension should be diagnosed if blood pressure is less than $100 / 70 \mathrm{~mm} \mathrm{Hg}$ in adults (18 years or older). ${ }^{11}$

After preliminary analysis of the HCCSCA data set, we first excluded pregnant women who had secondary hypotension due to primary conditions such as anorexia nervosa or Addison's disease. Pregnant women with orthostatic hypotension were also excluded because the aim of this study was the evaluation of primary or essential hypotension in pregnant women. In the second step, we evaluated hypotension in pregnant women according to the source of information. Two groups of primary hypotension could be differentiated: (i) prospectively and medically recorded hypotension in the prenatal maternity chart and (ii) hypotension based on only retrospective maternal information in the questionnaire. Blood pressure was measured by qualified nurses at each prenatal clinic visit and was recorded by obstetricians in the prenatal maternity chart. In general, hypotension in pregnant women was diagnosed at the first prenatal clinic visit. If these pregnant women had normal or high blood pressure in later prenatal care visits, and it was recorded in the prenatal maternity chart, they were excluded from the study. The validity of a hypotension diagnosis in pregnant women without mentioning it in the prenatal maternity chart is questionable; ${ }^{9}$ therefore, we decided to evaluate only prospectively and medically recorded hypotension in the prenatal maternity chart.

Hypotension-related drug treatments were also evaluated. Other potential confounding factors included maternal age, birth order (or parity; that is, if there was no previous delivery, birth order is one) and marital and employment status as indicators of socioeconomic status (the latter two factors showed a good correlation with education level and income ${ }^{12}$ ), as well as maternal diseases and pregnancy supplements, particularly folic acid and multivitamins, which were all indicators of the standard of preconceptional and prenatal care. In addition, periconceptional folic acid and/or folic acid-containing multivitamin supplementation can prevent certain CAs such as neural-tube defects, ${ }^{13-15}$ cardiovascular CA, urinary tract defects and congenital limb deficiencies. ${ }^{16-19}$ Only one type of $3 \mathrm{mg}$ folic acid tablet was available in Hungary during the study period. Folic acid-containing micronutrient combinations, (that is, multivitamins) had folic acid doses ranging from 0.1 to $1 \mathrm{mg}$ per tablet.

The aim of this study was to evaluate pregnancy complications and adverse birth outcomes. Pregnancy complications were recorded by medical doctors in 
the prenatal maternity chart. Among adverse birth outcomes, beyond the previously mentioned CAs, the rates of preterm births and low birthweight newborns were evaluated. Gestational age was calculated from the first day of the last menstrual period. Three time intervals were considered. (i) The first month of gestation preceding organogenesis. The first two weeks are preconception, whereas the third and fourth weeks comprise the preimplantation and implantation period of zygotes and blastocysts, which contain omnipotent stem cells. Thus, CAs cannot be induced by environmental effects in the first month of gestation, and this accounts for the 'all-or-nothing effect' (that is, total loss or normal further development). (ii) The second and third months of gestation are the sensitive 'critical period' for most major CAs. (iii) The fourth to ninth months of gestation are the postorganogenesis period of pregnancy. The definition of preterm births was a birth before the 37th gestational week (or 259 days), whereas the definition of low birthweight was $<2500 \mathrm{~g}$.

\section{Statistical methods}

We used SAS version 8.02 (SAS Institute, Cary, NC, USA) for statistical analyses. Contingency tables were prepared for the main study variables. First, the characteristics of pregnant women with hypotension were compared with those of all pregnant women without hypotension as a reference. The $\chi^{2}$-test was used for categorical variables, whereas Student's $t$-test was used for quantitative variables. Second, pregnancy complications, maternal diseases and hypotension-related drug treatments were evaluated by ordinary logistic regression models and odds ratios (ORs), and their 95\% confidence intervals (CI) were calculated. Third, birth outcomes of newborn infants born to pregnant women with or without hypotension were compared. Finally, we compared the rate of hypotension during the study pregnancy in specified CA groups, including at least three case mothers who were hypotensive during pregnancy, and their matched controls. Adjusted ORs with 95\% CI were evaluated in conditional logistic regression models for the rate of hypotension. We examined confounding variables by comparing the OR for hypotension in the model with and without inclusion of potential confounding variables. Finally, maternal age ( $<20,20-29$ and $>30$ years), birth order (first delivery or one or more previous deliveries), employment status and hypotension-related drug intake (yes/no) were included in the models as potential confounders.

\section{RESULTS}

The case group consisted of 22843 malformed newborns or fetuses ('informative offspring'), and 537 (2.35\%) had mothers with medically recorded hypotension in the prenatal maternity chart. The total number of births in Hungary was 2146574 during the 1980-1996 study period. Thus, the 38151 controls represented $1.8 \%$ of all Hungarian births. Of these 38151 controls, 1268 (3.32\%) were born to mothers with medically recorded hypotension.

In general, hypotension in pregnant women was diagnosed at the first visit in the prenatal care clinic and confirmed by blood pressure measurements in later visits. However, of the 537 case mothers, 262 $(48.8 \%)$ were aware of having hypotension previously; therefore, this condition was considered chronic. Of the 1268 control mothers, 652 $(51.4 \%)$ had been previously diagnosed with chronic hypotension. The rest of the pregnant women received the diagnosis of hypotension after the third gestational month because of a delayed first prenatal care clinic visit, or they had new-onset hypotension during pregnancy.

The main variables of mothers with hypotension compared with pregnant women without hypotension as reference are shown in Table 1. This comparison indicates a somewhat lower mean maternal age, both in the hypotensive case and control mothers, because of the

Table 1 Maternal variables of case and control mothers with and without hypotension as reference

\begin{tabular}{|c|c|c|c|c|c|c|c|c|c|}
\hline \multirow{3}{*}{$\begin{array}{l}\text { Variable } \\
\text { Quantitative }\end{array}$} & \multicolumn{4}{|c|}{ Case mothers } & \multicolumn{4}{|c|}{ Control mothers } & \multirow{3}{*}{$\begin{array}{l}\text { Comparison between case and } \\
\text { control mothers with hypotension }\end{array}$} \\
\hline & \multicolumn{2}{|c|}{$\begin{array}{l}\text { Without hypotension } \\
\qquad(\mathrm{N}=22306)\end{array}$} & \multicolumn{2}{|c|}{$\begin{array}{l}\text { With hypotension } \\
\qquad(\mathrm{N}=537)\end{array}$} & \multicolumn{2}{|c|}{$\begin{array}{l}\text { Without hypotension } \\
\qquad(\mathrm{N}=36883)\end{array}$} & \multicolumn{2}{|c|}{$\begin{array}{l}\text { With hypotension } \\
\qquad(\mathrm{N}=1268)\end{array}$} & \\
\hline & No. & $\%$ & No. & $\%$ & No. & $\%$ & No. & $\%$ & \\
\hline \multicolumn{10}{|l|}{ Maternal age (years) } \\
\hline$\leqslant 19$ & 2436 & 10.9 & 70 & 13.0 & 3123 & 8.5 & 154 & 12.2 & \\
\hline $20-29$ & 15219 & 68.2 & 374 & 69.5 & 26697 & 72.4 & 905 & 71.4 & $\chi_{2}^{2}=0.6, P=0.76$ \\
\hline$\geqslant 30$ & 4651 & 20.9 & 93 & 17.3 & 7063 & 19.1 & 209 & 16.5 & \\
\hline Mean \pm s.d. & \multicolumn{2}{|c|}{$25.5 \pm 5.3$} & \multicolumn{2}{|c|}{$24.9 \pm 5.1$} & \multicolumn{2}{|c|}{$25.5 \pm 4.9$} & \multicolumn{2}{|c|}{$24.9 \pm 4.8$} & $t=0.1, P=0.91$ \\
\hline \multicolumn{10}{|l|}{ Birth order } \\
\hline 1 & 10459 & 46.9 & 249 & 46.3 & 17602 & 47.7 & 607 & 47.9 & $\chi_{1}^{2}=0.3, P=0.56$ \\
\hline$\geqslant 2$ & 11847 & 53.1 & 288 & 53.7 & 19281 & 52.3 & 661 & 52.1 & \\
\hline Mean \pm s.d. & \multicolumn{2}{|c|}{$1.9 \pm 1.1$} & \multicolumn{2}{|c|}{$1.9 \pm 1.2$} & \multicolumn{2}{|c|}{$1.7 \pm 0.9$} & \multicolumn{2}{|c|}{$1.7 \pm 0.9$} & $t=2.2, P=0.03$ \\
\hline \multicolumn{10}{|l|}{ Categorical } \\
\hline Unmarried & 1238 & 5.6 & 31 & 5.8 & 1426 & 3.9 & 45 & 3.6 & $\chi_{1}^{2}=4.6, P=0.03$ \\
\hline \multicolumn{10}{|l|}{ Employment status } \\
\hline Professional & 1860 & 8.3 & 41 & 7.6 & 4225 & 11.5 & 128 & 10.1 & \\
\hline Managerial & 4868 & 21.8 & 100 & 18.6 & 9861 & 26.7 & 273 & 21.5 & \\
\hline Skilled worker & 6164 & 27.6 & 165 & 30.7 & 11282 & 30.6 & 408 & 32.2 & \\
\hline Semiskilled worker & 3772 & 16.9 & 97 & 18.1 & 5571 & 15.1 & 212 & 16.7 & $\chi_{6}^{2}=29.6, P<0.001$ \\
\hline Unskilled worker & 1466 & 6.6 & 37 & 6.9 & 1802 & 4.9 & 57 & 4.5 & \\
\hline Housewife & 2090 & 9.4 & 38 & 7.1 & 2006 & 5.4 & 32 & 2.5 & \\
\hline Other & 2086 & 9.3 & 59 & 11.0 & 2136 & 5.8 & 158 & 12.5 & \\
\hline Pregnancy supplements & & & & & & & & & OR (with 95\% Cl) \\
\hline Folic acid & 11008 & 49.4 & 271 & 50.5 & 20076 & 54.4 & 699 & 55.1 & $0.8(0.7-1.0)$ \\
\hline Multivitamins & 1271 & 5.7 & 59 & 11.0 & 2342 & 6.3 & 167 & 13.2 & $0.8(0.6-1.1)$ \\
\hline
\end{tabular}

Abbreviations: $\mathrm{Cl}$, confidence interval; OR, odds ratio; s.d., standard deviation. 
Table 2 Prevalence of medically recorded pregnancy complications in case and control mothers with or without hypotension

\begin{tabular}{|c|c|c|c|c|c|c|c|c|c|c|}
\hline \multirow[b]{3}{*}{ Pregnancy complication } & \multicolumn{4}{|c|}{ Case mothers } & \multicolumn{4}{|c|}{ Control mothers } & & \\
\hline & \multicolumn{2}{|c|}{$\begin{array}{l}\text { Without hypotension } \\
\qquad(\mathrm{N}=22306)\end{array}$} & \multicolumn{2}{|c|}{$\begin{array}{l}\text { With hypotension } \\
\qquad(\mathrm{N}=537)\end{array}$} & \multicolumn{2}{|c|}{$\begin{array}{l}\text { Without hypotension } \\
\qquad(\mathrm{N}=36883)\end{array}$} & \multicolumn{2}{|c|}{$\begin{array}{l}\text { Hypotension with } \\
\qquad(\mathrm{N}=1268)\end{array}$} & \multicolumn{2}{|c|}{$\begin{array}{c}\text { Comparison of case and contro } \\
\text { mothers with hypotension }\end{array}$} \\
\hline & No. & $\%$ & No. & $\%$ & No. & $\%$ & No. & $\%$ & $O R$ & $95 \% \mathrm{Cl}$ \\
\hline Severe nausea or vomiting & 1683 & 7.5 & 63 & 11.7 & 3666 & 9.9 & 203 & 16.0 & 0.7 & $0.5-0.9$ \\
\hline Gestational hypertension & 575 & 2.6 & 0 & 0.0 & 1082 & 2.9 & 0 & 0.0 & - & \\
\hline Placental disorders ${ }^{\mathrm{a}}$ & 287 & 1.3 & 7 & 1.3 & 575 & 1.6 & 17 & 1.3 & 1.0 & $0.4-2.3$ \\
\hline Polyhydramnios & 205 & 0.9 & 7 & 1.3 & 180 & 0.5 & 11 & 0.9 & 1.5 & $0.6-3.9$ \\
\hline Threatened preterm delivery ${ }^{b}$ & 2783 & 12.5 & 67 & 12.5 & 5803 & 15.7 & 183 & 14.4 & 0.8 & $0.6-1.1$ \\
\hline Gestational diabetes & 140 & 0.6 & 1 & 0.2 & 261 & 0.7 & 9 & 0.7 & 0.3 & $0.0-2.1$ \\
\hline Anemia & 3091 & 13.9 & 149 & 27.7 & 5992 & 16.2 & 364 & 28.7 & 1.0 & $0.8-1.2$ \\
\hline
\end{tabular}

Abbreviations: $\mathrm{CI}$, confidence interval; OR, odds ratio.

aplacenta previa, premature separation of placenta, antepartum hemorrhage.

${ }^{\mathrm{b}}$ Cervical incompetence as well.

larger proportion of women less than 20 years of age. However, the same mean maternal age associated with a significantly higher birth order in case mothers than in control mothers. In addition, the proportion of professional/managerial women was higher in control mothers with hypotension than in case mothers with hypotension.

The proportion of folic acid and multivitamin supplementation during pregnancy was higher in control mothers than in case mothers. However, the daily number of folic acid tablets was similar in case and control mothers; therefore, we combined these two groups. We found that one ( $3 \mathrm{mg})$, two $(6 \mathrm{mg})$ and three $(9 \mathrm{mg})$ tablets were used by 22 , 69 and $9 \%$ of pregnant women, respectively. Thus, the estimated daily dose was $5.6 \mathrm{mg}$. The estimated daily dose of folic acid was $0.85 \mathrm{mg}$ in the multivitamins used by all pregnant women in the study.

In the study group, 2640 pregnant women were visited at home, and their smoking habits were evaluated on the basis of 'family consensus'. Hypotension was recorded in 98 (3.7\%) pregnant women, and $9(9.2 \%)$ smoked during the study pregnancy. Of the 2542 pregnant women without hypotension, 571 (22.5\%) smoked. Of the 800 control mothers visited at home, 31 (3.9\%) were diagnosed with hypotension and $3(9.7 \%)$ smoked. Finally, of the 769 pregnant women without hypotension, 149 (19.4\%) were smokers. The proportion of hard and regular drinkers during pregnancy was about $1 \%$ without significant difference among the study groups.

Among acute maternal diseases, only influenza and the common cold (generally with secondary complications) occurred more frequently in both case $(29.4$ vs. $21.6 \%)$ and control (21.6 vs. $18.4 \%)$ mothers with hypotension as compared with pregnant women without hypotension. Among chronic diseases, only hemorrhoids were recorded more frequently in case $(4.8 v s .2 .4 \%)$ and control $(5.0 v s$. $3.3 \%)$ mothers with hypotension. The occurrence of migraines in case (2.8 vs. $2.4 \%)$ and control (2.8 vs. $1.8 \%$ ) pregnant women with or without hypotension did not show obvious differences.

Pregnancy complications showed characteristic patterns in pregnant women with hypotension (Table 2). Gestational hypotension could not occur due to exclusion criteria, but the incidence of preeclampsia was also lower in pregnant women with hypotension. In addition, the incidence of severe nausea or vomiting, threatened abortion and particularly anemia was higher in pregnant women with hypotension compared with pregnant women without hypotension. When comparing pregnancy complications between case and control mothers with hypotension, only the incidence of severe nausea or vomiting in pregnancy showed significant difference; it was lower in case mothers with hypotension.

The first choice drug for the treatment of hypotensive persons was pholedrine in Hungary during the study period. Nearly half of case $(50.2 \%)$ and control (48.3\%) pregnant women with hypotension were treated orally by pholedrine drops, whereas only about $2 \%$ of pregnant women without hypotension received this drug. Ephedrine was used rarely in case $(2.4 \%)$ and control $(2.0 \%)$ pregnant women with hypotension.

The birth outcomes of case and control mothers with hypotension and without hypotension did not show significant differences. Here, only the data of control newborns are presented because CAs have a more drastic effect on gestational age and birth weight than does maternal hypotension. There was no difference in the sex ratio between the study groups. The mean gestational age at delivery (39.4 weeks) was the same, and the mean birthweights (3288 vs. $3275 \mathrm{~g}$ ) were similar in the groups of mothers with or without hypotension. The rate of preterm births (8.6 vs. 9.2\%) and of low birthweight newborns (4.2 vs. 5.7\%) was somewhat lower in the group of pregnant women with hypotension; however, these differences did not reach the level of significance.

Finally, we evaluated the possible association of pregnant women with medically recorded hypotension during any time of pregnancy and in the second and/or third gestational months with the risk of different CAs in informative offspring, and compared it with the rate of medically recorded hypotension with a similar time window in control mothers who delivered the matched controls of cases (Table 3). The diagnosis of hypotension was medically recorded in several pregnant women after the third gestational month. The adjusted OR showed a significantly lower risk of total CAs in the offspring of pregnant women with hypotension at any time during pregnancy. This finding is explained by the additive effect of the lowered risk associated with hypotension in $10 \mathrm{CA}$ groups of cases born to mothers with hypotension. The adjusted OR also did not show an association between maternal hypotension in the second and/ 
Table 3 Results of conditional logistic regression analysis of cases with different CAs and all matched controls without CA to estimate the association between maternal hypotension and the risk of different CAs

\begin{tabular}{|c|c|c|c|c|c|c|c|c|c|}
\hline \multirow[b]{2}{*}{ Study group } & \multirow[b]{2}{*}{ Total no. } & \multicolumn{2}{|c|}{$\begin{array}{l}\text { Second and/or third } \\
\text { gestational month }\end{array}$} & \multicolumn{2}{|c|}{ Adjusted } & \multicolumn{2}{|c|}{ Any time during } & \multicolumn{2}{|c|}{ Adjusted } \\
\hline & & No. & $\%$ & OR & $95 \% \mathrm{Cl}^{\mathrm{a}}$ & No. & $\%$ & OR & $95 \% \mathrm{Cl}^{\mathrm{a}}$ \\
\hline Controls & 38151 & 293 & 0.77 & & rence & 1268 & 3.32 & & rence \\
\hline \multicolumn{10}{|l|}{ Isolated CAs } \\
\hline Neural-tube defects & 1202 & 7 & 0.58 & 1.3 & $0.5-3.5$ & 37 & 3.08 & 1.1 & $0.7-1.7$ \\
\hline Cleft lip \pm palate & 1375 & 21 & 1.52 & 1.3 & $0.7-2.3$ & 43 & 3.13 & 0.9 & $0.6-1.3$ \\
\hline Cleft palate only & 601 & 6 & 1.00 & 1.2 & $0.4-3.7$ & 8 & 1.33 & 0.4 & $0.2-0.9$ \\
\hline Rectal/anal atresia/stenosis & 231 & 0 & 0.00 & - & & 4 & 1.73 & 0.7 & $0.2-2.5$ \\
\hline Renal a/dysgenesis & 126 & 3 & 2.38 & 6.6 & $0.6-71.4$ & 7 & 5.56 & 1.6 & $0.5-5.6$ \\
\hline Obstructive CAs of urinary tract & 343 & 3 & 0.87 & 4.5 & $0.4-46.7$ & 8 & 2.33 & 0.4 & $0.2-0.9$ \\
\hline Hypospadias & 3038 & 15 & 0.49 & 0.6 & $0.3-1.1$ & 61 & 2.01 & 0.5 & $0.4-0.7$ \\
\hline Undescended testis & 2052 & 8 & 0.39 & 0.8 & $0.3-2.0$ & 45 & 2.19 & 0.6 & $0.4-0.9$ \\
\hline Exomphalos/gastroschisis & 255 & 1 & 0.39 & 1.9 & $0.2-23.1$ & 7 & 2.75 & 1.5 & $0.5-4.3$ \\
\hline Microcephaly, primary & 111 & 0 & 0.00 & - & & 3 & 2.70 & 1.3 & $0.3-6.6$ \\
\hline Congenital hydrocephaly & 314 & 2 & 0.64 & 2.3 & $0.3-17.9$ & 6 & 1.91 & 0.5 & $0.2-1.4$ \\
\hline CAs of eye & 99 & 0 & 0.00 & - & & 4 & 4.04 & 2.8 & $0.3-27.9$ \\
\hline CAs of ear & 354 & 3 & 0.85 & 0.6 & $0.2-2.6$ & 13 & 3.67 & 1.1 & $0.5-2.4$ \\
\hline Cardiovascular CAs & 4480 & 23 & 0.51 & 0.8 & $0.5-1.3$ & 106 & 2.37 & 0.7 & $0.6-0.9$ \\
\hline CAs of genital organs & 127 & 1 & 0.79 & 0.6 & $0.1-7.1$ & 3 & 2.36 & 0.8 & $0.2-3.5$ \\
\hline Clubfoot & 2424 & 19 & 0.78 & 0.7 & $0.4-1.3$ & 66 & 2.72 & 0.7 & $0.5-0.9$ \\
\hline Limb deficiencies & 548 & 4 & 0.73 & 0.6 & $0.2-1.7$ & 13 & 2.37 & 0.6 & $0.3-1.2$ \\
\hline Poly/syndactyly & 1744 & 9 & 0.52 & 0.6 & $0.3-1.3$ & 40 & 2.29 & 0.6 & $0.4-0.8$ \\
\hline CAs of musculo-skeletal system & 585 & 4 & 0.68 & 0.6 & $0.2-1.9$ & 6 & 1.03 & 0.4 & $0.1-0.9$ \\
\hline CAs of diaphragm & 244 & 1 & 0.41 & 0.6 & $0.0-8.5$ & 4 & 1.64 & 0.8 & $0.2-2.6$ \\
\hline Other isolated CAs & 1241 & 11 & 0.90 & 0.8 & $0.4-1.6$ & 30 & 2.42 & 0.5 & $0.3-0.8$ \\
\hline Multiple CAs & 1349 & 4 & 0.30 & 0.4 & $0.1-1.2$ & 23 & 1.70 & 0.4 & $0.3-0.7$ \\
\hline Total & 22843 & 145 & 0.63 & 0.8 & $0.7-0.9$ & 537 & 2.35 & 0.66 & $0.49-0.84$ \\
\hline
\end{tabular}

Abbreviations: $\mathrm{CA}$, congenital abnormality; $\mathrm{Cl}$, confidence interval; OR, odds ratio.

a Maternal age $(<20,20-29$ and $>30$ years), birth order (first delivery or one or more previous deliveries), employment status, related drug intake for hypotension (i.e., pholedrine and ephedrine) (yes/no).

or third gestational months and a higher risk of CAs of any type, and the adjusted OR (with 95\% CI) was also less than 1 in the total CA group. However, there was no specified CA group with a lower risk in this time window.

In the next step, we differentiated severe-treated and mild-untreated hypotensive pregnant women, but there was no significant difference in the adjusted OR of overall CAs or specific CA groups between the former two subgroups. However, the adjusted OR (with 95\% CI) for total CAs in informative offspring of hypotensive pregnant women without folic acid or folic acid-containing multivitamin supplementation in the first trimester was $0.9(0.8-1.1)$. Thus, this approach showed the beneficial effect of folic acid and multivitamin supplementation in early pregnancy for the prevention of some CAs.

\section{DISCUSSION}

The first controlled epidemiological study regarding the possible association of hypotension in pregnant women with pregnancy complications and adverse birth outcomes resulted in three important findings in our large, population-based data set.

(1) Maternal hypotension is protective against preeclampsia.

(2) There was a higher risk for severe nausea or vomiting, threatened abortion and anemia in pregnant women with hypotension.
(3) A higher rate of adverse birth outcomes (that is, CAs, preterm births and/or low birthweight newborns) was not found in the children of pregnant women with hypotension. In fact, the rates of these variables in the total CA group were lower in the informative offspring of pregnant women with hypotension.

The prevalence of prospective and medically recorded hypotension was $3.3 \%$ in Hungarian pregnant women who later delivered babies without CAs, whereas this rate was $2.4 \%$ in the mothers of children with CAs during the 1980-1996 study period.

Primary hypotension is a symptom of low blood pressure based on an individual's genetic background. There is a marked early fall in diastolic and systolic blood pressures (averages $7 \mathrm{~mm} \mathrm{Hg}$ ) due to systematic vascular resistance during pregnancy, ${ }^{20}$ and this phenomenon can explain new-onset hypotension in pregnant women. However, about half of the pregnant women had chronic hypotension in this study, and these women were treated with pholedrine or ephedrine.

Our study showed that primary hypotension in pregnant women is a protective factor against preeclampsia. The opposite trend, namely, preeclampsia superimposed on chronic hypertension, ${ }^{11,21,22}$ is well known.

There was a higher rate of threatened abortion based on vaginal bleeding with or without permanent uterine spasm in pregnant 
women with hypotension, particularly among control mothers. This pregnancy complication was recorded in the prenatal maternity chart; that is, the diagnosis can be considered as objective. Unfortunately, the occurrence of early fetal deaths (for example, miscarriages) is not recorded in the HCCSCA; thus, we cannot measure whether the higher risk of threatened abortion is associated with a higher rate of early fetal death. However, pregnant women with threatened abortion in the study had no miscarriages and later delivered.

Pregnant women with hypotension had a higher occurrence of severe nausea or vomiting in the study. Our previous study showed that severe nausea or vomiting in pregnancy resulted in some protective effect for several CAs. ${ }^{23}$ Thus, our hypothesis is that there is some relationship between maternal hypotension and the higher incidence of severe nausea or vomiting in pregnant women. Together, they may be associated with a mild protective effect against some CAs. Although nausea or vomiting can reflect an intrinsic anomaly of the stomach, these symptoms may be associated with central nervous system pathology. For example, the chemoreceptor trigger zone, located in the area postrema of the brain stem, is close to the 'vomiting center', which includes the motor nuclei of cranial nerves, among them the dorsal motor nucleus of the vagus. ${ }^{24}$ This region is sensitive to several signals, including the effect of human chorionic gonadotropin and thyroxin. The cyclical levels of these hormones are higher in pregnant women with nausea or vomiting. ${ }^{25}$

Our pregnant women with hypotension also had a higher occurrence of anemia, which may be related to increased risk of bleeding secondary to higher frequencies of hemorrhoids in this group. ${ }^{26}$ In Hungary, most anemia during pregnancy is caused by iron deficiency. More than two-thirds of pregnant women were treated with iron, and about one-tenth were treated with iron-containing micronutrient ('multivitamin') products. Finally, it can be concluded that some relationship between anemia and hypotension cannot be excluded.

The findings of experimental animal investigations showed that alterations in utero-placental perfusion affect the growth and status of the placenta, as well as the fetus. ${ }^{27} \mathrm{~A}$ decreased blood-flow index was found in pregnant women who had fetuses with intrauterine growth retardation. ${ }^{28}$ Nevertheless, a higher risk for low birthweight newborns was not found in pregnant women with hypotension; thus, the maternal cardiovascular system must be able to adapt to the lower blood pressure.

CAs were not more prevalent in the offspring of pregnant women with hypotension, and this finding is an important indirect argument for the lack of a teratogenic effect of the drugs (that is, pholedrine and ephedrine) used for the treatment of maternal hypotension during pregnancy. Previously, studies on the teratogenic potential of pholedrine had not been published. ${ }^{5}$ Our recent population-based casecontrol study does not show any teratogenic potential of pholedrine. ${ }^{29}$ Heinonen et al..$^{30}$ evaluated 373 offspring of women exposed to ephedrine in the first four lunar months, and 17 offspring were affected with CAs (relative risk: 0.98). Werler et al. ${ }^{31}$ also did not find any association between maternal ephedrine use during the first trimester of pregnancy and various CAs.

Our hypothesis regarding the unexpected association of maternal hypotension with lower risk for total CA is based on the combination of three factors: (i) a healthier lifestyle indicated by a lower prevalence of smoking during the study pregnancy, (ii) a higher incidence of severe nausea or vomiting in pregnancy associated with a lower risk of CAs and (iii) the CA-preventive effect of folic acid and multivitamins during early pregnancy ${ }^{13-19}$ in about half of the hypotensive pregnant women.

The strengths of the HCCSCA are that it is a population-based large data set including 1805 pregnant women with prospectively and medically recorded hypotension in an ethnically homogeneous Hungarian (Caucasian) population. We were able to differentiate the different types of hypotension; pregnant women with secondary and orthostatic hypotension were excluded. Additional strengths are the matching of cases to controls without CAs, available data for potential confounders and medically recorded gestational age at delivery and birthweight. Finally, the diagnosis of medically reported CAs was checked in the $\mathrm{HCAR}^{7}$ and later modified, if necessary, on the basis of recent medical examination within the HCCSCA. ${ }^{7}$

However, this data set also has limitations. We did not have any details regarding the onset of chronic hypotension before the study pregnancy. In general, concrete systolic and diastolic blood pressure values were recorded in the prenatal maternity chart. Unfortunately, we did not copy these changing figures, and recorded only the diagnosis of hypotension. Thus, we were unable to consider the severity of hypotension, although the differentiation of treated and non-treated forms helped to categorize the condition. Other pregnancy outcomes (for example, miscarriages) were not recorded in the HCCSCA. We did not know the lifestyle of the total data set because of the unreliable retrospective self-reported data of mothers regarding their smoking and drinking habits. ${ }^{32}$ However, these data were available in subgroups of 2640 non-respondent case and 800 control mothers obtained by regional nurses who visited them at home and achieved a 'family consensus' through cross-interviews of family members.

In conclusion, a higher risk for CAs and other adverse birth outcomes was not found in the children of pregnant women with hypotension, but maternal hypotension was associated with a higher risk for some pregnancy complications.

\section{CONFLICT OF INTEREST}

The authors declare no conflict of interest.

1 Roberts JM. Pregnancy-related hypertension. In Creasy RK, Resnik R, lams JD (eds), Maternal-Fetal Medicine. Principles and Practice, 5th edn. Saunders: Philadelphia, 2004, pp 859-899.

2 Churchill $D$. The new American guidelines on the hypertensive disorders of pregnancy. $J$ Hum Hypertens 2001; 15: 583-585.

3 Gifford R, August P, Cunningham G, Lindheimer MD, McNellis D, Roberts JM, Sibai BM, Taler SJ. Report of the National High Blood Pressure Education Program Working Group on High Blood Pressure in Pregnancy. Am J Obstet Gynecol 2000; 183: S1-15.

4 Creasy RK, Resnik R, lams JD (eds). Maternal-Fetal Medicine. Principles and Practice, 5th edn. Saunders: Philadelphia, 2004

5 Shepard TH, Lemire RJ. Catalog of Teratogenic Agents, 11th edn. Johns Hopkins University Press: Baltimore, 2004.

6 Czeizel AE, Rockenbauer M, Siffel C, Varga E. Description and mission evaluation of the Hungarian Case-Control Surveillance of Congenital Abnormalities, 1980-1996. Teratology 2001; 63: 176-185.

7 Czeizel AE. The first 25 years of the Hungarian Congenital Abnormality Registry. Teratology 1997; 55: 299-305.

8 Czeizel AE, Intödy Zs, Modell B. What proportion of congenital abnormalities can be prevented? Br Med J 1993; 306: 499-503.

9 Czeizel AE, Petik D, Vargha P. Validation studies of drug exposures in pregnant women. Pharmacoepid Drug Safety 2003; 2: 409-416.

10 Czeizel AE, Vargha P. Periconceptional folic acid/multivitamin supplementation and twin pregnancy. Am J Obstet Gynecol 2004; 191: 790-794.

11 Rashidi A, Rachman M, Wright JT. Diagnosis and treatment of hypertension. In: Fuster V, Walsh RA, O'Rourke RA, Poole-Wilson P (eds). Hurst's The Heart, 12th edn. McGraw Hill Medical: New York, NY, 2008, pp 1610-1629.

12 Puho E, Métneki J, Czeizel AE. Maternal employment status and isolated orofacial clefts in Hungary. Cent Eur J Publ Health 2005; 13: 144-148.

13 MRC Vitamin Study Research Group. Prevention of neural tube defects: results of the Medical Research Council vitamin study. Lancet 1991; 338: 131-137.

14 Czeizel AE, Dudás I. Prevention of the first occurrence of neural-tube defects by periconceptional vitamin supplementation. N Engl J Med 1992; 327: 1832-1835.

15 Berry RJ, Li Z, Erickson JD, Moore CA, Wang H, Mulinare J, Zhao P, Wong LY, Gindler J, Hong SX, Correa A. Prevention of neural tube defects with folic acid in China. China-US Collaborative Project for Neural Tube Defect Prevention. N Engl J Med 1999; 341: 1485-1490 
16 Czeizel AE. Reduction of urinary tract and cardiovascular defects by periconceptional multivitamin supplementation. Am J Med Genet 1996; 62: 179-183.

17 Czeizel AE, Dobo M, Vargha P. Hungarian cohort-controlled trial of periconceptional multivitamin supplementation shows reduction in certain congenital abnormalities. Birth Defects Res (Part A) 2004; 70: 853-861.

18 Botto LD, Olney RS, Erickson JD. Vitamin supplements and the risk for congenital anomalies other than neural tube defects. Am J Med Genet Part C 2004; 125C: 12-21.

19 Czeizel AE. Periconceptional folic acid and multivitamin supplementation for the prevention of neural tube defects and other congenital abnormalities. Birth Defects Res (Part A) 2009; 85: 260-268.

20 McAnulty JH, Brober CS, Metcalfe J. Heart disease and pregnancy. In: Fuster V, Walsh RA, O'Rourke RA, Poole-Wilson P (eds). Hurst's The Heart, 12th edn. McGraw Hill Medical: New York, etc, 2008, pp 2188-2202.

21 Brown MA, Lindheimer MD, de Swiet M, Van Assche A, Moutquin JH. The classification and diagnosis of the hypertensive disorders of pregnancy: Statement from the International Society for the Study of Hypertension in Pregnancy (ISSHP). Hypert Pregnancy 2001; 20: ix-xiv.

22 Chobanian AV, Bakris GL, Black HR, Cushman WC, Green LA, Izzo JL, Jones DW, Materson BJ, Oparil S, Wright Jr JT, Roccella EJ, National Heart, Lung and Blood Institute Joint National Committee on Prevention, Detection, Evaluation, and Treatment of High Blood Pressure, national High Blood Pressure Education Program Coordinating of Committee. The seventh report of the Joint National Committee on Prevention, Detection, Evaluation and Treatment of High Blood Pressure: the JNC 7 report. JAMA 2003; 289: 2560-2572.
23 Czeizel AE, Puho E, Ács N, Bánhidy F. Inverse association between severe nausea and vomiting in pregnancy and some congenital abnormalities. Am J Med Genet 2006; 140A: 453-462.

24 Koch KL. Approach to the patient with nausea and vomiting. In: Yamada T (ed). Textbook of Gastroenterology, 2nd edn. Lippincott JB: Philadelphia, 1955, pp 731-740.

25 Jamfelt-Samsioe A. Nausea and vomiting in pregnancy: A review. Obstet Gynecol Surg 1987; 42É: 422-431.

26 Weakley FL. Anal and perinatal lesions. In: Farmer RG, Achkar E, Fleshler B (eds). Clinical Gastroenterology. Raven Press: New York, 1983, pp 401-407.

27 Resnik R, Creasy RK. Intrauterine growth restriction. In: Creasy RK, Resnik R, lams JD (eds). Maternal-Fetal Medicine. Principles and Practice, 5th edn. Saunders: Philadelphia, 2004, pp 495-512.

28 Lunell NO, Nyland L. Uteroplacental blood flow. Clin Obstet Gynecol 1992; 35: 108-113.

29 Bánhidy F, Ács N, Puhó HE, Czeizel AE. Teratogenic potential of pholedrine, a sympathomimetic vasoconstrictive drug-a population-based case-control study. Cong Anom 2010; 50: 122-128.

30 Heinonen OP, Slone D, Shapiro S. Birth Defects and Drugs in Pregnancy. John Wright Publishing Sciences Group: Littleton, MA, 1977, pp 345-356.

31 Werler MM, Mitchell AA, Shapiro S. First trimester maternal medication use in relation to gastroschisis. Teratology 1992; 45: 361-367.

32 Czeizel AE, Petik D, Puhó E. Smoking and alcohol drinking during pregnancy. The reliability of retrospective maternal self-reported information. Cent Eur J Publ HIth 2004; 12: 179-183. 